\title{
Inclusive University didactics and technological devices: a case study
}

\author{
Catia Giaconi', Arianna Tadder², Noemi Del Bianco3, Simone Aparecida Capellinit
}

\begin{abstract}
This paper provides a review of projects related to new technologies used to favour the teaching-learning processes and the inclusive practices in the University context for students with disabilities and with Specific Learning Disorders. Authors present a review of strategies, trajectories and perspectives activated in the national and international scene, aiming to guarantee a significant pedagogical framework of reference. Furthermore, the paper focuses on a meaningful path activated at the University of Macerata, the project Inclusion 3.0, a relevant example of new technologies in support of teachinglearning processes and inclusion practices among all students.
\end{abstract}

Keywords: inclusive university, didactics practices, technological devices.

\section{Conceptual state of the art}

The aim of this article is to contribute to the development, dissemination, improvement and consolidation of didactic planning itineraries and inclusive practices through an integrated system of technologies to favour the teachinglearning processes in University classes for students with disabilities and with Specific Learning Disorder.

${ }^{1}$ Catia Giaconi, Full Professor of Didactic and Special Padagogy, Department of Education, Cultural Heritage and Tourism, University of Macerata, Italy. In the shared design of the article, Catia Giaconi has edited the writing of pages 1-8.

${ }^{2}$ Arianna Taddei, Researcher of Didactic and Special Pedagogy, Department of Education, Cultural Heritage and Tourism, University of Macerata, Italy. In the shared design of the article, Arianna Taddei has edited the writing of pages 16-24; 28-30.

${ }^{3}$ Noemi Del Bianco, PhD in Human Sciences, Department of Education, Cultural Heritage and Tourism, University of Macerata, Italy. In the shared design of the article, Noemi Del Bianco has edited the writing of pages 9-16; 25-27.

${ }^{4}$ Simone Aparecida Capellini, Full Professor of Speech and Hearing Sciences Department, São Paulo State University "Júlio de Mesquita Fiho"- UNESP, Marília, São Paulo, Brazil. In the shared design of the article, Simone Aparecida Capellini has edited the writing of pages 1-8. 
The topic taken into consideration is developed specifically through the project Inclusion 3.0, led at the University of Macerata, started on 25 July 2017, a case study that is inserted into an international and national overview on the services for the disability, which we will illustrate in the paper.

The program looks at the implementation of micro-planning and macroplanning actions in the direction of the University inclusion of students with disabilities or with Specific Learning Disorders. The project focuses its intervention strategy on enhancing the university services and on awareness events at national and international level aiming to improve political and scientific guidelines in addition to the development of support processes for teaching, educational mediation, and evaluation.

The significance of this project line is partially at macro level and connected with the international scenarios, and in particular with the European Horizon 2020 program, at micro level it conforms with the national trend of enrolling students with disabilities and Specific Learning Disorders in the Universities, this brings along the need to track University teaching trails oriented to personalization, inclusion and innovation.

Concerning the macro-level, project Inclusion 3.0 respects entirely the diversified strategies identified by the European Commission. Therefore, Horizon 2020's funds will focus, as outlined in PART III - "Challenges for the Society" - on a specific objective: "Europe in a changing world inclusive, innovative and reflexive societies" to understand the ongoing social transformations and suggest solutions, promoting a creative and innovative culture. Phenomena such as the growth of the Internet, digital divide, the financial systems or the ageing of the economy clearly show that it is necessary to think and respond to these issues in all their aspects of inclusion and innovation at the same time.

The intrinsic complexity of these challenges and the evolution of the needs makes it therefore essential to develop innovative research, new and intelligent technologies, processes and methods, mechanisms of social innovation, coordinated actions and policies that anticipate or influence Europe's main future developments. In order to understand, analyze and build inclusive, innovative and reflective societies, Europe needs a response to free the potential to share ideas in the future to create new knowledge, technologies and capabilities.

The main directives of the activities in the "inclusive Societies" focus on the understanding and promotion or implementation of the following elements, which are fundamental also in the project that we are mentioning. They concern:

"a) the mechanisms to promote an intelligent, sustainable and inclusive growth; 
b) the trusted organizations, the practices, policies and services that are necessary to build adaptable, inclusive, participative, open and creative societies in Europe, keeping in account especially migration, integration and demographic changes;

c) the role of Europe on the world-scale, concerning especially human rights and justice in the world;

d) the promotion of sustainable and inclusive environments through territorial and urban planning and design".

To nurture and encourage greater inclusion of people with disabilities and SpLDs during university courses through the development of methodologies, assessment of frameworks and indicators that will be responsive to the needs of everyone.

The areas for intervention planned by Inclusion 3.0 concern innovative practices and multidisciplinary procedures to be used at different levels in the University context, able to respond promptly to the needs of students, even with disabilities and SpLDs, thus ensuring greater usability and inclusion. Inclusion 3.0 fits perfectly the "inclusive, innovative and reflective" objective in the scenario proposed by Horizon 2020, reachable with avant-garde science and interdisciplinary approach, technological progress and organizational innovations.

The further junction proposed in Horizon 2020, specifically PART I, "Scientific Excellence" is articulated in four specific objectives, including the point "Emerging and Future Technologies (EFT)". It supports collaborative research to expand the capacity of Europe to produce cutting-edge innovations capable of revolutionizing traditional thinking. It stimulates interdisciplinary scientific collaboration on the basis of radically new, high-risk ideas, accelerating the development of the most promising emerging scientific and technological sectors as well as the Union-wide structuring of the corresponding scientific communities.

The project Inclusion 3.0, with the EFT production, promotes research and technology beyond what is already known, encouraging new and visionary thinking to open promising routes toward new technological forms, some of them being likely to develop guiding paradigms in the technological and intellectual contexts over the next decades. To achieve the objective of promoting innovative technologies that offer the possibility of opening new ways of teaching and, at the same time, of guaranteeing access to university learning for people with disabilities and SpLDs.

In the PART II of Horizon 2020, "Industrial Leadership" points to "Information and communication technologies (ICT)" as innovative modalities capable to cover generic programmes of research and innovation. A series of activity guidelines aim to tackle the challenges of industrial and technological leaderships within ICT, especially: 
“a) a new generation of components and systems: integrated engineering, advanced and efficient components and systems concerning resources and energies;

b) next generation elaborations: advanced and safe technologies of elaboration, including cloud computing;

c) Internet of the future: software, hardware, infrastructures, technologies and services;

d) Technologies of information contents and administration: ICT for the digital contents and for cultural and creative industries;

e) advanced interfaces and robots: robotics and intelligent environments;

f) Microelectronics and photonics: essential enabling technologies related to micro and nanotechnologies, and photonic, including quantum technologies".

Specifically, Inclusion 3.0 results in line with the proposals of Horizon 2020, tightly connected to letters c) and d), because the University of Macerata has activated within its infrastructures technologies and services for the digital contents to support university teaching and favour the students with disabilities and SpLDs.

In line with the flagship initiative "A Digital Agenda for Europe" (COM (2010) 0245), the specific objective of research and innovation (R \& I) in ICT is to support, develop and exploit opportunities offered by the progress made in the ICT sector for the benefit of all, towards the full use of new technologies and the use of technological aid able to guarantee greater accessibility of information.

At micro-level, Inclusion 3.0 project is inserted to provide innovative and sustainable perspectives following the increase in enrolment of students with disabilities and with Specific Learning Disorders within the University. In the chapter "Training processes" of the $51^{\text {st }}$ Report on the social situation of the Country/2017, the Censis (Report 2017) photographs and confirms the growing trend of students with disabilities and dyslexia in the last decade, also in the university.

The Censis survey, which involved 40 Universities $(65 \%$ of the Italian universities), highlights that during the school year 2014-2015, the number of students with disability (legal level of disability $>66 \%$ ) and with SpLDs enrolled was 14.649 , corresponding to 10.2 per thousand. The overall growth was $+13.3 \%(+1.4 \%$ students with disability and $+108.3 \%$ students with SpLDs). In 2014-2015, the students were distributed as follows: $33.1 \%$ in human sciences and training areas, $29.3 \%$ sciences, $27.7 \%$ economy-law $9.9 \%$ medicine. Using the data of the Operative Units (O.U.) of this project as a reference, the growth of the phenomenon was confirmed also for the next school years according to the documentation of the aforementioned Censis Report, as shown by the following data for year 2015-2016 provided by the disability student services of the each university (set up as a follow-up to Law 17/99). 
Going in the specificities of school year 2015-2016, the University of Macerata presented 23 students with Specific Learning Disorders (SpLDs) and 106 students with disabilities; the University of Siena recorded 32 students with SpLDs and 133 students with disabilities; the University of Bologna presented 331 students with SpLDs and 524 students with disabilities, Marche Polytechnic University recorded 50 students with SpLDs and 174 students with disabilities. The data, still under elaboration by the disabled students services of UNISI and UNIPM signal a growing trend in years 2016/2017 and 2017/2018; the data already elaborated by the disabled students services of UNIMC and UNIBO report: 29 students with SpLDs and 126 students with disabilities in UNIMC for school year 2016/2017, 33 students with SpLDs and 146 students with disabilities for 2017/2018; 467 students with SpLDs and 625 students with disabilities in 2016/2017 in UNIBO, 470 students with SpLDs and 630 students with disabilities for 2017/2018.

The second micro-level emergency is closely linked to the previous one and it also emerges from the Censis survey following a research with university students with disabilities and SpLDs (chapter "Training processes" of the 51st Report on the social situation of the Country/2017). The survey shows that students with disabilities and SpLDs, while highlighting an adequate level of satisfaction in reference to the service orientation and disability of the universities, underline the need to improve access to teaching materials (37.4\%) and to have technological aid (36.5\%), as well as to find a greater relational and didactic availability on the part of the teachers (26.1\%). Therefore, this requires being able to rethink forms of support for university teaching, especially to design environments that have within them an integrated system of technologies capable of creating accessible, usable and sustainable multimedia materials.

Therefore, the data collected by Censis and those provided by the services of the O.U., show how the number of students with disabilities and SpLDs is significantly increasing in the high education system, thus posing new challenges and needs to be met. Students with disabilities and SpLDs constitute a particularly delicate type of users, followed by specific requests for more accessible teaching material, usability and technological aid.

A further contribution, in support of the abovementioned data related to the area of services for didactics and learning, is found in the studies carried out in the Italian and international university environment on students with disabilities (Aune, 1996; Berry \& Mellard, 2002; Cabral, 2013; CEE-Helios II, 1996; de Anna, 2016a; Hurst, 1993). Such investigations raised questions related to university teaching, finding, among the main critical points, "a scarce propensity, among many teachers, to change their teachings through a transformation of the contents, a transformation of the lecturing didactics 
adapted to the difficulties of the students and/or considering the different styles of learning" (de Anna, Covelli, 2018, p. 334).

Some of these problems may derive from "technical" difficulties of the teachers who do not possess an adequate dominion of the ITC, as emerged from studies carried out in a research on the training of the teachers I schools of all levels (Sanchez Utgé, Mazzer, Pagliara \& de Anna, 2017).

Furthermore, the experiences developed by the working group CNUDD "Improvement of the quality of inclusive didactics" highlight how reception, intended as strategy of support to direct and accompany the entire educational community, is a founding element to start and support inclusion in the universities, making university life closer to the students and facilitating their access to the necessary services and information for an effective integration (de Anna, Covelli, 2018, p. 338).

Concerning the state of the art, in the scientific and social fields, interest recently grew to understand and evaluate how the continuous and different applications of cutting-edge technologies, the fields of information and communication can improve the quality of information and communication perceived by the subjects (Ridolfi, 2002; Besio, 2006; Pinnelli, 2011, Giaconi, 2015). In this direction, the technological sector has a great potential to explore and improve the accessibility for the users in relation to multiple areas of intervention for university students with disabilities and SpLDs. Using available or innovative technology is not enough to realize a good system adaptable also to students with disabilities and SpLDs. To pursue this direction, a crucial element is the accessibility and usability of the system by teachers and students with disabilities and SpLDs. It is necessary to look at the technology in an innovative way, from the point of view of the real users who will have to use it, taking into account their needs.

The adoption of the User-Centerd Design (UCD) paradigm guarantees to satisfy the satisfaction and usability criteria of the technology under development, based on the continuous involvement of the end users during all the project and design phases of the proposed solution, seeking emancipation. The UCD process consists in designing the technology around user requirements (Quesenbery, 2005; ITEA, 2007). Developing a technology that can be used by the users of reference requires a detailed analysis of the users' needs, and their attitude towards technology and the direct involvement of users and the evaluation of the proposed technology (McCreadie et al., 2005; Marcellini et al., 2002).

In fact, Assistive Technologies (ATs) are tools and technical solutions, hardware and software that allow the disabled person to access information and services provided by the information systems, by overcoming or reducing 
the disadvantaged conditions. This is realized using special hardware and software instruments that allow conversion the information not available to the user from a format to another, accessible, one (the Braille bar, voice synthesis, voice recognition), or offer a mode of use of the devices with an input suited to the needs of the person (special computer mice, special keyboards, on-screen text magnifiers). ATs play a very important role in education and learning in general. They are the keystones of an inclusive and effective educational process, which is aimed at disabled students. Students with disabilities are often trapped in a vicious circle of exclusion from education and social life due to the lack of necessary support and the lack of means for equal participation. The primary objective of the use of new technologies in education for students with disabilities and special needs is precisely to promote equity in education and training opportunities.

They can support and help the full participation of these students in the learning process, both by allowing them to overcome the disadvantage and by overcoming the barriers created by traditional educational methodologies. Effective technological integration can provide all students with access to all levels of education, offering them tools or aid to complete their work more easily and independently, and even perform tasks that they previously were unable to achieve. Thanks to the new ATs, disabled students can develop a more active role at school and/or university, increase their involvement in learning and, consequently, develop autonomy.

New technologies offer enormous opportunities for the effective realization of an inclusive educational and social context that promotes the full participation of all students in learning and in classroom life while respecting diversity, different needs and abilities, characteristics and student learning expectations. Moreover, this context makes it possible to achieve a real integration process, in which the removal of all obstacles to participation and learning takes place through a different structuring of the teaching environment, a renewal of teaching methods, and training of the teaching staff towards the full use of new technologies and the use of technological aid that can guarantee greater information accessibility.

An overview of the main presently commercialized ATs, for people with disabilities and SpLDs, go from voice synthesis (Carlo II), to screen readers (JAWS, VoiceOver), Braille displays, pocket Braille or Notex Braille, screen magnifiers (ZoomText, Supernova, Magic), to voice recognition software (Dragon Naturally Speaking), direct subtitling systems (VoiceMeeting) direct or deferred translation (VoiceTranscribe), systems of augmented alternative communication (Picture Communication Symbols (PCS) and Bliss) and Vocal Output Communication Aids (VOCAs) portable machines that allow the user to select and transfer icon messages with the voice. 
Mainly, three factors affect the effectiveness and efficiency of a technological aid:

1. the correct identification of the most appropriate product for the characteristics of the subject in accordance with the tasks to be performed, the context and the degree of acceptability tolerated by the user;

2. integration of the products found in point 1 ;

3. deployment of the integrated solution of point 2 , through the identification of an appropriate configuration of the aiding tool, user training, supporting competence of assistants or teachers, level of accessibility of the physical environment.

\section{International overview on University systems for students with disabilities}

Turning the attention beyond the European borders, we find highly qualified training offers with inclusive characteristics by international universities, which moved to favour of full curricular participation for students with special learning needs a long time ago. The main aim of some institutions was to specialize in refined technological supports, attempting to reach high level programmes in some specific disabilities. This trend allows institutions to provide better conditions that can make the transition moment from home into college life more gradual and comfortable, building up relevant "bridges" that prepare the person to the independent life (Giaconi, 2015). The international Universities listed below have shown strong programming and solid support services even more a consistent value and priority for meeting the physical, social and academic needs of students with learning disabilities and special needs. With remarkable programmes (that offer support, tutoring and special courses designed to make everything less stressful for enrolees) these excellent schools are some of the best at committing resources and funding to equipping their students with Assistive Technology and tools they need, to not only become a successful student in the classroom, but also a valuable member of the student community as a whole on the campus. Specifically, we remark the following international institutions:

1. Rochester Institute of Technology

2. Griffith University ${ }^{6}$,

3. University of Arizona

\footnotetext{
${ }^{5}$ www.rit.edu/.

${ }^{6}$ www.griffith.edu.au/.

${ }^{7}$ www.arizona.edu/.
} 
4. University of Michigan ${ }^{8}$;

5. University of Connecticut ${ }^{9}$.

Emphasizing career education, Rochester Institute of Technology (RIT) in Rochester, NY, is a privately endowed, coeducational university with one of the most accessible communities available for deaf and hard-of-hearing students. These students can pursue associate degree programs in one of the nine colleges of the RIT, the college of National Technical Institute for the Deaf (NTID) with courses taught using direct instruction or they can pursue bachelor degree programs in the other seven colleges of RIT using a wide range of educational access services. NTID was established in 1968 to reverse the long history of under-employment and unemployment among U.S. nation's deaf and hard-of-hearing citizens. Today more than 1,300 deaf and hard-ofhearing students study, share residence halls, and enjoy social life together with 16,000 hearing students on the RIT campus, in what is widely regarded as the largest "mainstreamed" program in the world. The Technological Education Center for Deaf and Hard-of-Hearing Students (DeafTEC) ${ }^{10}$, administered by faculty at the National Technical Institute for the Deaf, is a National Science Foundation-funded Center of Excellence, one of approximately 40 Centers across the United States and overseen by a National Visiting Committee made up of professionals in academia and industry. DeafTEC is unique in the fact that its focus is on a particular audience, deaf and hard-of-hearing students, rather than on a technical discipline, providing one of the most accessible education communities in the world for deaf and hard-of-hearing students. The goal of DeafTEC is to successfully integrate more deaf and hard-of-hearing individuals into the workplace in highly skilled technician jobs in which these individuals are currently under-represented and underutilized. To achieve this goal, DeafTEC designed a comprehensive website to serve as a clearinghouse for information related to technological education and technician careers for deaf and hard-of-hearing students. A few examples of services that support students success at RIT are: Career-Focused Associate Degree Programs, to communicate directly with deaf and hard-of-hearing students using a variety of communication strategies, which may include sign language with voice, sign language without voice, spoken language (FM systems are available), fingerspelling, printed/visual aids, web-based instructional materials and individual tutoring (an assigned counsellor work closely with the student to help him to plan collegiate experience and provide him with personal, social, career and

\footnotetext{
${ }^{8}$ www.umich.edu/.

${ }^{9}$ https://csd.uconn.edu/csdtech/.

${ }^{10}$ www.deaftec.org/.
} 
academic advising and counselling services); Interpreting, in fact RIT has the largest staff of professional sign language interpreters of any college program in the world, providing around 149,000 hours of interpreting services. In addition to classroom interpreting, the student also may request interpreting services for non-academic activities such as athletic events, religious services, student government meetings, guest presentations and other student life activities; Note taking, trained student note takers record information during class or laboratory lectures, discussions and multimedia presentations. The resulting class notes are uploaded to the web, so the student can easily access them; Real-time Captioning Services, to provide a comprehensive English text display of classroom lectures and discussion. Students read this text during class and may print it as a permanent record of class discussions; Personal FM Systems and FM Systems Installed in more than 30 venues at RIT, including general classrooms, laboratories, auditoriums and theatres. Signage outside the venue indicates that there is a system present and informs the user where the receivers can be obtained (e.g. box office, sound control booth, HelpDesk).

The Disabilities Service in Griffith University, located in Australia, supports students, who have a wide range of disabilities or conditions including, but not limited to Autism Spectrum Disorders, Hearing impairments, Learning difficulties, Injuries that are temporary, Medical conditions, Mental health conditions, Mobility issues, Vision impairments, etc. The University campusbased Disabilities Service Officers can assist all students with: arranging alternative exam conditions such as additional time, separate venues, equipment etc, formatting print materials into other formats; captioning or transcription of audio-visual materials; access to assistive technologies; access to note taking services; access Auslan interpreting services; access to participation assistants or other support as appropriate. Specifically Griffith University has had a Deaf and Hard of Hearing Student Support Program for more than 30 years and customizes support and activities for this cohort of students. The establishment of Griffith University's Deaf Student Support Program (DSSP) in 1985 was a milestone in Australian education. When it was first established the Program had a focus on making the breakthrough to preparing/supporting deaf students to become teachers of the deaf themselves ${ }^{11}$. Today thanks to the DSSP a large number of facilities and resources are accessible to all students: eight assistive technology labs across five campuses, contain hardware and Software tailored to students who are vision-impaired or have a learning or physical disability. Workstations in the labs contain: screen-enlargement software (JAWS Screen Reader); screen-reading software (ZoomText); voice-recognition

${ }^{11}$ www.unapeda.asso.fr/article.php3?id_article=454\#university; www.griffith.edu.au/studentservices/diversity-inclusion/transition-and-disabilities. 
software (Dragon NaturallySpeaking); word-processing software for users with reading and writing difficulties (Read\&Write); a Braille embosser; scanner and laser printer; document magnification resources. This service is free available to academic staff, professional staff, undergraduate students, postgraduate students, alumni, students and staff from other institutions and visitors. In this direction, remarkable is that at Griffith the goal is to ensure students, but also working staff, to participate fully in all spheres of employment and study without barriers. A key priority of the University is to create an inclusive environment for prospective and current staff with disabilities. They welcome applications for employment from people with disabilities and are ready to provide whatever support staff with a disability may need in their workplace. In keeping with strategic commitment to accessibility and inclusion through the Disability Action Plan, there is a specific site, called "Accessibility and Inclusion" that aims to provide supports across all areas of the University with guidance on ensuring accessibility across the physical, digital and learning environments. This site provides practical assistance for staff to ensure full accessibility and inclusion for all staff, students and the wider community, building awareness and capacity among Griffith community towards best practice.

Students with disability at the University of Arizona, Tucson, are served by the Strategic Alternative Learning Techniques Center (SALT) ${ }^{12}$, the leading comprehensive academic support program for college students who learn differently. With over 500 students taking advantage of the services it offers, the center is a comfortable place and caters to a wide range of needs, because the technology and its surrounding learning space is designed to support the mobile needs of the modern student. Students can access tutoring and computer labs as well as workshops, to help with the transition. They are assigned a Strategic Learning Specialist, who will create a unique learning plan designed to help them succeed at a higher level in their college coursework. The SALT Center space encourages a "bring-your-own-device" approach, with lounge furniture that offers flexible seating to comfortably facilitate studying via personal laptops, and shared-screen technology that provides options for connecting smaller devices to larger screens for individual and group study.

The Student Lounge contains a variety of soft, modular furniture, with personal tables, built-in privacy screens, as well as power outlets, and charging stations for mobile devices. Added touches, such as acoustic ceiling tiles for noise reduction, an abundance of natural light, and a soft stream of music, create an environment conducive to deep concentration

12 http://salt.arizona.edu/students/technology-collaboration-and-productivity; www.salt. arizona.edu/. 
and focus. On any given day, multiple students utilize the lounge to study, complete homework, and relax in between tutoring sessions. In addition to functioning as a communal area, the lounge also serves as a space for peer tech coaches to showcase software and apps that promote academic success. The Tech Bar features six high-resolution 24" monitors, equipped with multiple connections for easy hook-up to individual laptops. The larger monitor provides more screen real estate by serving as a second display for greater productivity. Students may display an article or textbook on one screen while showing a paper or assignment on the other. This setup allows students to easily refer to content on both screens without having to switch between windows, increasing focus and reducing distractions. In the SALT Center there are also Collaboration Stations, open to groups for studying and working together on projects, where students may also share laptop screens and even mobile device displays to 60" LED screens. A large, interactive touch-screen in the Math \& Science Lab features the ability to incorporate multi-sensory learning modalities into tutoring sessions. The multi-sensory approach maximizes audio, visual, kinesthetic, and tactile inputs for integrated knowledge acquisition. Involving multiple modalities in the learning process creates meaningful connections and provides the opportunity for higher-ordered thinking through three-dimensional application, analysis, and synthesis. Everything that the student and tutor create together may be captured and shared with the student for future follow-up and review. Educational technology team guides students to apps and tools that provide accessibility to course material and support individual learning styles. The team also assists students with using innovative technology throughout the building. A student Tech Coach or the Educational Technology Coordinator support Focus Areas, such as: Online learning platforms used by UA courses; Catmail \& Calendars; Apps for studying, time management, organization and mind mapping; Audio Note Taking Apps and the Smart Pen (Audio Note Taking apps on laptops and tablets capture the entire lecture and empower students to review key concepts and fill in missing items. It offers great benefits to students struggling with Dysgraphia, ADHD, Auditory Processing, etc.), Read and Write Gold. The UA software license site provides free access to this software to all of its students to install on their personal devices. Both Windows and Mac versions are available for: Text-tospeech; Audio Files; Voice recognition; Highlighting tools; Collect Highlights; Dictionary; Mind Mapping.

One of the most representative in U.S. is the University of Michigan (UM), located in Ann Arbor, Michigan, just 40 miles west of Detroit. Service to the disabled student body came into focus at Michigan just five months after the Vocational Rehabilitation Act of 1973 when the university officially recognized the Office of Disabled Student Services. The office was renamed 
Services for Students with Disabilities (SSD) in 1989 and since then the organization has advocated for students with disabilities at state, national and even international levels. The SSD was the first to establish "an adaptive technology computing lab and together with the Provost's office a fund to support mandated accommodations". Many major universities nationwide have since repeated these trailblazing efforts. The SSD, whose services are free to students, features Modern Language Aptitude Testing throughout the year and maintains the well-resourced HathiTrust Digital Library. The University of Michigan is committed to supporting those with accessibility needs. There are several ongoing and project activities that are currently underway across the university to help improve accessibility to technology for students, faculty, and staff with disabilities. A sampling of these activities includes: The Assistive Tech department is funded and staffed within the Consumer Technology group of Information and Technology Services (ITS). This department helps provide assistive technology at Sites workstations and serves as an information resource for the entire school; The university has a dedicated Web Accessibility Coordinator, who works to provide students, faculty, and staff with support and advice on how to make websites accessible. The coordinator maintains the Web Accessibility at the U-M website to share techniques, tools, and advice about making websites accessible; $U-M$ Council for Disability Concerns (CfDC) meets monthly to address disability issues affecting the University of Michigan community; Services for Students with Disabilities (SSD) exists as a student advocacy agency and has many services for disabled students, including captioning of video, note-taking, and facilitating the loaning of adaptive equipment and materials; The University has established the Adaptive Technology Computing Site (Knox Center) in the Shapiro Undergraduate Library. The site is open to students registered with SSD, and provides a quiet working environment with all the assistive technology available on other Sites machines plus some additional equipment. Specialized hardware and software is provided at multiple Windows and Macintosh computers, all of which have 21 " or larger high-resolution monitors. All workstations also have adjustableheight work surfaces to accommodate wheelchairs or people who wish to stand. One reclining chair is available, and the other chairs are fully adjustable. One workstation has a video magnifier. The Knox Center has three computers with voice recognition software: two Windows machines running Dragon NaturallySpeaking and one Mac running Dragon for Mac; In late-November 2011, the IT Executive Committee decided that Google has demonstrated an appropriate commitment to accessibility, and that U-M would move forward with the implementation of Google Apps for Education. This implementation is one of several initiatives designed to support U-M's academic, teaching, research, and clinical programs by investing in the next generation of IT 
services and computing technologies. U-M is committed to an implementation strategy that balances the greater benefits of this initiative with the needs of the disabled members of the U-M community. Google has made significant improvements to the accessibility of Google Apps for Education and continues to work on bettering the accessibility of its products. U-M and peer institutions that have also implemented Google Apps for Education are closely tracking these activities. U-M believes one of the best ways to get accessible tools to the U-M community is to continue to work with Google and other vendors to mature their tools.

The University of Connecticut (UC) started with the Program for the Physically Handicapped in 1967, and in June of 1977, Section 504 of the Rehabilitation Act of 1973 was put into effect at the University, making it a requirement that equal opportunities and access be granted to students with disabilities. As a result, the UC continuously modified ramps, doors, lavatories, sidewalks and installed elevators in inaccessible buildings, for this reason was voted one of the Top Ten Disability-Friendly Colleges in 1999 by New Mobility Magazine ${ }^{13}$. It was not until 1992 that the office was named "The Center for Students with Disabilities"(CSD) and today the CSD has a large staff that includes over 200 student employees (strategic choice to encourage mutual help) while the campus currently provides 11 accessible residence halls to its over 700 students with disabilities. CSD services have academic advising and technology assistance through a program called CSDTech, that provide students with disabilities the opportunity to access learning technologies that aim to enhance overall success and independence, build self-confidence, autonomy and skills when using technology-related tools. CSDTech provides students a platform to explore educational technologies and guide them to find technological tools to meet their individual needs and learning styles. The main goal is to increase student engagement in the classroom by providing them with the tools they need to actively participate in a dynamic learning community that includes lectures, discussions, multi-media presentations, labs, field studies, and other pedagogical methods. The CSDTech's Team supports every student in finding the right learning tools to meet individual needs and learning styles, constantly researching applications, software programs, other resources and devices that can help building academic or life skills and can be utilized to help benefit student population. A wide variety of solutions are offered to help accommodate students, including assessments and demonstrations, access to educational software, and equipment loans. Specific types of Assistive Technology and software can be used in and out of the classroom to help improve note taking, studying, and over all education, such

${ }^{13}$ https://csd.uconn.edu/history/. 
as Inspiration, Dragon, JAWS, etc. and offer licenses for the following software: Read \& Write; Sonocent Audio Notetaker; Audionote and Kurzweil. Majority of the recommendations that are offered have free versions or trials that can be upgraded if the student likes it. Constant research on rising technology and software are added to a dedicated web page, divided in specific category, where is possible to find a large number of supports. Same categories are: Text-toSpeech/Literacy Software; Note-taking; Writing Support/Organization; Speech Input; Study Aids; Time Management/Organization; Health and Wellness; Anxiety and Meditation.

\section{National overview on the supporting services for students with disabilities and ASD in the Italian Universities}

The process of inclusion of students with disabilities and ASD in the Italian university courses is supported by specific normative laws to safeguard and guarantee to right to study of which we list below the main laws of reference:

- Law n. 104, 5 February 1992, "Framework-law for the assistance, social integration and rights of handicapped persons".

- Law n. 17, 28 January 1999, "Integration and modification of the Framework-law n. 104, 5 February 1992, for the assistance, social integration and rights of handicapped persons".

- Law n. 4, 9 January 2004, "Legal provisions to favour the access to information tools for subjects with disabilities".

- Law n. 18, March 2009, "Ratification and execution of the Convention of the United Nations on the rights of people with disabilities, with optional protocol, signed in New York on December 132006 and institution of the National Observatory on the conditions of people with disabilities".

- Law n. 170, 8 October 2010, "New standards regarding specific learning disorders at school" and relative Guidelines.

In particular, Law n. 17, 28 January 1999, "Integration and modification of the Framework-law n. 104, 5 February 1992, for the assistance, social integration and rights of handicapped persons" contemplates a number of activities that Universities must implement to ensure the integration of disabled students in the university courses. The services that must be provided by the universities concern: technical and teaching subsidies, institution of special services of tutelage, individualized treatment to pass the exams. Universities must reserve a quote of the University Ordinary Funds (UOF), the Dean nominates a teacher delegated to the diversity responsible for coordinating, monitoring and supporting the implementation of the initiatives regarding the process of integration of the students with disabilities (CNUDD, 2014, p. 2). The 
constant need of sharing practices and experiences developed by the single Universities on the theme was at the basis of the constitution, in 2001, of a intra-university coordinating body called "National University Conference of the Delegates for the Disability (Conferenza Nazionale Universitaria dei Delegati per la Disabilità-CNUDD)". The collaboration between the CRUI and the CNUDD enhanced the redaction of the early guidelines towards a common perspective for the efforts of the Italian universities on integration: an effort based on the provision of similar services among various Universities and on the principles of "reception, participation, autonomy and integration for the students with disabilities, whom must be provided with equal opportunities of training, study and research, while promoting awareness for the academic community on the themes of diversity and disability" (CNUDD, 2014, p.2). The Guidelines underwent revision according to the evolution of the legislation and the experience developed by the different actors. The updated version (2014) includes a specific section for the students with ASD. The general objective of the document is to "address the policies and the good practices of the Universities, stimulating exchanges and synergies within the scope of a greater qualification of the right to study for those students with special learning needs and the constitution of inclusive academic communities" (CNUDD, 2014, p. 3). As highlighted by the Guidelines, it is essential that each University "establish a supporting administrative structure, coordinated by the Delegate". The latter has a strategic role in facilitating the services for students with disabilities and ASD, specifically: firstly, it is the reference point in the University for all questions concerning the theme; also, represents the reference for all realities outside the University that are involved with disabilities and ASD (for example, a regional agencies for the right to study, associations and firms for labour insertion); promotes the process of awareness in his/her the academic community, through the realisation of targeted initiatives; is responsible for coordinating and monitoring the offered services to guarantee the development within an inclusive perspective; finally, takes the role of mediator between students and teachers, raising awareness on integration.

We proceed now with the analysis of the present overview on the Italian universities in relation to the services dedicated to the students with disabilities. Generally speaking, and on the basis of the CNUDD's (2014) Guidelines referred above, most Italian Universities have established a Disabilities and ASD Service (SDDA) "in some instances, they established real dedicated offices, in others, through operational or personnel units within pre-existing administrative structures". As reported in CNUDD's guidelines, the main tasks assigned to SDDA we highlight:

- "The interface function between the university system and the students, as well as the families and the territorial and health systems; 
- The link with the academy services and, in particular, with tutorials and in and out orientation;

- The itinerant personalized accompaniment to enhance the academic success;

- The administrative organisation and management to provide the services and the monitoring of their efficacy;

- The support activity for the Delegate and, when envisaged, to the single referents of the University structures".

In general, the services for students with disabilities should be equipped with personnel with relational competence and related to the concession of specific technical and information aids.

At national level, the state of the art of the SDDA's services, briefly exposed below, has been measured by a survey carried out on the sites of 77 Universities that adhered to the CNUDD. The data gathered would need verification through a field study capable to analyse effectively the presence of indicators of quality in the activities of each individual service. Here, we limit ourselves to the illustration of some general considerations based on the online survey and the results of studies carried out at national level. The goal is to identify possible perspectives of further development and improvement of the quality of the services provided to guarantee the right to study to students with disabilities, hence, an improvement of the levels of inclusion in the context of university teaching-learning.

A first consideration concerns the denomination that the services take in the various Universities: in some instances - although limited in number - a scarce attention towards the language adopted in the last years in accordance with people with disabilities emerges. In fact, in several cases expressions like "handicap carriers" were recorded used to specify the target of some SDDA. Furthermore, a deeper research carried out beyond the consultation of the pages dedicated to the services for disabilities, highlights how, at times, the specific SDDA links do not show important quality initiatives developed by the various Departments to favour inclusion ${ }^{14}$.

The web pages dedicated to present the types of services offered to the students with disabilities usually include a short description of the actions contemplated within the Guidelines of CNUDD 2014, which are then systematically presented and are measured transversely in most Universities, even when taking different denomination and operative declination.

\footnotetext{
${ }^{14}$ One example is the Inclusion Technologies Laboratory, Lab-Int, established since 2001 at the Department of Education Sciences of the University of Bologna. It is an area dedicated to the realization of projects, initiatives, research activities within the field of inclusion didatics with the support of ICT. For more information http://laboratori.edu.unibo.it/about/lab-intlaboratorio-inclusione-e-tecnologie/.
} 
The first support contemplated by the services is tutelage, it refers to an activity aimed to support students with disabilities to ease their social integration in the University, increase students' autonomy, set interventions aimed to create a more inclusive environment. Generally, the service is offered when a student specifically asks for it and on the basis of the analysis of the needs seen during the itineraries of personalisation. The activity may consist of: "accompaniment by an student of the same course in learning activities; support to individual studies by a tutor with specific skills [...] to overcome the exams or the writing of the final work; the accompaniment of a specialized figure to support communication" (CNUDD, 2014, p. 8).

An essential service concerns assistance to the mobility of the person. The role of such service is to guarantee the students full access to the university buildings, coordinating possible interventions to eliminate architectural barriers, with the other offices of the University. Furthermore, many Universities are engaged to sustain the mobility of students with disabilities, easing the movements to reach the location of the university and for the movement inside the structures of the universities, obviously depending of the quantity of the available resources. Some Universities reported the stipulation of agreements with transport companies within the region that offered the services at reduced moderate prices.

An especially cared for invoice for the services, albeit implemented at different levels as highlighted at the beginning of our paper, concerns the access to the teaching materials and the availability of specific technologies. It is indeed one of the most important services, especially today considering the strategic role of the new technologies and ICTs (information and communication technologies) in the teaching-learning process, especially at university level in an autonomous perspective in the evolution of the studies for the students with disabilities and ASD. Among the most used teaching supports, we remind: "voice synthesis software, voice recognition, voice interface, word prediction, emulators of the pointing system, wider keyboards, optic pointers, hardware and software video-wideners" (CNUDD, 2014, p. 9), which are often associated to the use of accessible teaching material. According to CNUDD guidelines the types of supports are chosen with the students and can be requested from the local health services, when contemplated by the law.

In the guidelines, there are indications on the modes of verification of the exams. The service is usually provided upon the request of a student and is built around the characteristics of the individual case, through diversified modalities: allowance for extended duration, adoption of technical and supporting tools, and more, taking into account the guidelines of Law 170/2010 for the cases of Specific Learning Disorders. 
For what concerns the support for international mobility, as remarked by CNUDD, it is necessary to act for the promotion and effective support for increased availability. The SDDA service, apart from easing the contact with foreign universities, should also concern raising awareness among the students who could take the role of escorts or tutors to accompany the courses of youngsters with disabilities. Likewise, SDDA services must be able to receive foreign students with disabilities who study in the Italian universities.

The service is supported by a constant orientating action. Overall, orientation represents an essential service to accompany positively the phase of transition of the students with disabilities from secondary school to the university, playing also a preventive role in relation to the risk of early abandonment of the courses. The orientation accompaniment does not end at the moment of initial insertion or the attainment of the university degree: in fact, it remains essential also "in exiting", as the meeting device for the student with disabilities and the labour market. In this sense, the service should endeavour to raise awareness and collaborate with the territorial offices in charge for the seeking employment with the University's offices of Job Placement.

To integrate the above, it appears evident that each University stresses some types of services instead of others, depending also on the relative availability of the economic and human resources.

A strong point seen in many Universities is that of producing networks on the territory, establishing alliances with structures characterized by remarkable expertise on the theme inclusion and disability. The networks concretize especially on the theme of Orientation at the exit, connected with bridging the academic and professional trails: a delicate and complex phase in general, in particular for the inclusion of people with disabilities, which requires to be accompanied by raising awareness inside the business world. The network appears in the services presented on different university sites also with the capacity to involve the volunteering world: in fact, there are many universities that offer the opportunity to perform the Civil Service to young people in the context of the tutoring activities. Finally, it has been seen that in the North of Italy there are experimentations of practices to put in synergy the different services for disabilities of the Universities, of which the experience of the network of Coordination of the Lombard Universities for Disability (CALD, rete di Coordinamento degli Atenei Lombardi per la Disabilità), represents a good example. The network was set up by the Rectors' Delegates in 2011 to implement more effectively the regulations foreseen in the academic field to enhance full inclusion and participation of students with disabilities and ASD to university life ${ }^{15}$. The CALD presents a space for

${ }^{15}$ Such network is composed by the following universities:Università degli Studi di Milan, Università degli Studi di Pavia, Università degli Studi dell'Insubria, Università Commerciale 
research, a permanent dialogue on the theme of inclusion, with the objective of improving the conditions of integration and the quality of the right to study of the students with disabilities and ASD based also on sharing the good practices developed by the single universities and the creation of synergies through the planning of programmes and common perspectives. Beside the activity of research, CALD also offers areas for the assistance that include: labour insertions, psychiatric disorders, ASD - specific learning disorders, ICT University and Disability, relationship with the institutions, accessible bibliographic resources ${ }^{16}$.

Even considering the present short analysis, evidently, the role played over the years by the SDDA services became increasingly more strategic in easing the trail of integration in the courses for the students with disabilities and ASD, for this reason next we introduce the "Inclusion 3.0" project, as case study of actions of intervention aimed to promote inclusive actions within University contexts.

\section{A case study}

Since the school year 2016-2017, the University of Macerata is implementing, along with the service for disabilities, actions to favour an inclusive policy for students with disabilities and SpLDs, which merge in the project "Inclusion 3.0".

The motivations underlying this choice are to be found, on one hand, in the necessary attention, on the part of the Institutions, to young people with disabilities and their future, where the University can (and must) constitute a relevant experience of adulthood; on the other hand, it should increase the enrolments of students with disabilities and with Specific Learning Disorders. In such direction, the orientation and disabilities of our University records the passage from 26 students present in 2011 to 57 in 2016-2017 and 70 in 20172018, and registers the access of young people with Disorders of the Autistic Spectrum, and not only of students with physical and sensorial disabilities, or Specific Learning Disorders (Dyslexia, Dysgraphia, Dyorthography, Dyscalculia).

This reality requested the implementation of the following strategic lines that, with the surveys on national and international realities, allowed the accomplishment of inclusive university trails for students with disabilities.

Bocconi, Università Cattolica del Sacro Cuore, Università degli Studi di Milan - Bicocca, Università degli Studi di Bergamo, Università Carlo Cattaneo - LIUC, Libera Università di lingue e comunicazione - IULM, Politecnico di Milan, Università degli Studi di Brescia.

${ }^{16}$ More information on: www.cald.it/chi-siamo. 
The first line concerned implementing accessibility and usability of the information that the students with disabilities can encounter in the University's websites, but also of its manual sources. In fact, unlike other schools, the University does not possess a librarian system where the university texts accessible to students with sensorial disabilities (visual ad/or auditory) and for those with dyslexia. This caused the project to realize a number of guidelines for the students on the modes to obtain digital books according to the specificities of the single publishing houses, and with specific national agencies to adapt the texts for students with visual and/or auditory disabilities.

The second action guidelines contemplated the realization of "technological posts" for the studies with specific subsidies for students with disabilities and SpLDs. Each post is equipped with mouse scanners to digitalize pages and portions of texts, scanners for texts, screens for the visual-impaired, backlit keyboards, voice synthesis, software to produce conceptual maps and schemes, etc. a guide has been appointed to complete the posts, which will be updated annually, equipped with most functional and recent apps to facilitate taking notes (for example, the app "dragon dictation") and university studies for young people with disabilities and dyslexia. Within this line of intervention, educational actions were foreseen; they concern also specialized tutors who will accompany students with disabilities in their learning trails.

The third line of action saw the realization of specific projects to learn the Chinese language by students with dyslexia. This initiative was an important action not only at local level, but also above all internationally since the project ended with a summer camp in China and allowed students with dyslexia to confront specific ways of learning a foreign language.

The inclusiveness of the project also included several awareness-raising events and connections with the territory on the issues of disability and inclusion.

Among the events held we mention the first national award "Premio Inclusione 3.0" that awarded inclusive projects, at national and international level, conducted by schools, cooperatives, residential and day-care centers; and "Unimc for Inclusion", a week of cultural and art meetings on the theme of disabilities, which involved all University of Macerata's departments and the sector associations, setting up a supportive network for university inclusion.

\section{Reflections and Perspectives}

The overview conducted in this paper aims to highlight the highlights and shadows of the university inclusion process of students with disabilities and DSA. 
In addition to the Censis data indicated above, several research reports the critical issues still inherent in the university system for the full realization of inclusive routes in academic contexts. As also affirmed by De Anna and Covelli, "the different issues that emerged from the experiences and the related research must necessarily be addressed at the system level involving both the MIUR to define policies common to all the universities and their intervention strategies, the CNUDD-CRUI and Teaching Delegates on innovative projects" (de Anna, Covelli, 2018, p. 341). The results highlight the need to adopt systemic logics more adaptable to the development and implementation of inclusion processes, starting from interventions aimed at students with ASD for whom it is most appropriate to overcome a predominantly individual approach, sometimes simply related to the use of compensatory and exemption tools. The increase of the population of students with disabilities and ASD in the Italian universities, as shown by the Censis (2017) survey and the increased need for diversified answers to the multiple necessities, request better and increased accessibility and inclusion. In such perspective, the role played by the ICTs must be boosted working on the skills of operators and teachers, and building alliances with competent realities present on the territory.

Being able to use the right technologies and integrate them with scientific competence and awareness of the user's needs means changing the lives of the people involved, reducing the gap and difficulties, facilitating their integration and inclusion, making them interact constructively with others allowing them to develop their talents.

The development prospects are different, in line with what was previously described. The first prospect involves the implementation of technologies and university study method routes, using technologies for the support of disabled students and with ASD. The second one concerns the creation of supports for university teachers in the design of accessible and inclusive material. In reference to modern technologies, specifically ATs, and the solutions for implementing a digital environment can be varied, but the architectural keystone remains the interaction with the user, supported by the ability to learn and adapt (Serna et al., 2007). Knowing more about the state of the art consists in creating an integrated system of technologies able to lead the teachers in planning material and inclusive teaching itineraries, and also to support students with disabilities and SpLDs to find and interact with accessible materials and contents that answer their special learning needs.

Nevertheless, there is a clear divergence between the potential that could be reached with the technologies (assistive and non-assistive) for learning and their effective use. Teachers may be disoriented in front of a plethora of available tools, and find difficulties in using technologies to create pedagogically 
effective contents for learning. Consequently, in recent times, there has been a growing demand to create pedagogical planners (Grainne, 2012), developed mostly to support the planning for primary and secondary school teachers, to provide assistance and support.

The attempts on higher teaching levels, such as the university, are more recent and of lesser extension, innovative are Pedagogical Planner (P.P.) within the teaching planning at universities able to integrate multiple functions and technologies, succeeding where other planners failed: the accessibility also for people with disability or SpLDs. The specific literature of reference, therefore, highlights how the current tools called P.P. can be used for a variety of purposes: - as step-by-step guidance to help practitioners make theoretically informed decisions about the development of learning activities and choice of appropriate tools and resources to undertake them; - to inspire lecturers to adopt a new teaching strategy and support them in doing so (Falconer, Beetham, Oliver, Lockyer, \& Littlejohn, 2007); - to provide design ideas in a structured way - so that relations between design components are easy to understand (Goodyear, 2005); - to combine a clear description of the learning design and offer a rationale which bridges pedagogical philosophy, researchbased evidence and experiential knowledge (Goodyear, 2005); - as a database of existing learning activities and examples of good practice which can then be adapted and reused for different purposes (Goodyear, 2005); - as a mechanism for abstracting good practice and meta-models for learning (Conole \& Weller, 2007); - to produce a flowing learning design intended for the student's direct use (Falconer et al., 2007); or - to encode the designs in such a way that they supports an interactive, fluid, process of design (Goodyear, 2005). Some examples of projects and products activated by several universities, to favour technological modes of teaching support are: - The Learning Design Template Project at Queensland University of Technology (Heathcote, 2006); - Designing for active learning online with learning design templates at the University of New South Wales (McAlpine \& Allen, 2007); - The "Learning Designs" website at the University of Wollongong (Oliver, Harper, Hedberg, Wills, \& Agostinho, 2002); - The LearningMapR tool (Buzza \& Richards, 2005); - JISC-funded planner tools; - Phoebe (Manton \& Masterman, 2007); London Planner (Laurillard, 2008).

The objective of the planners is to provide a structured guide jointly with the resources to help teachers to design learning contents (Phoebe, 2009; DialogPlus Toolkit, 2014; CompendiumLD, 2018). They can be more or less integrated within the Virtual Learning Environments (VLEs), or a set of tools for teaching and learning, planned to improve the experience of learning for the students using the computer and Internet in a process of learning (JISC, 2007). In fact, the VLEs allow personalization of the learning functions and have the 
potential to satisfy the requests of diverse students (Dongming et al., 2014, Kurilovas et al., 2014). With the arrival of a new VLEs age, new methods are needed to support properly the interactions of learning (Eradze et al., 2014).

We believe that the development of these two perspectives may support the Universities in producing inclusive actions for university student's with ASD and disabilities, facilitating the experience of life at the university and accessible individualized modes of university studies.

\section{References}

Andò, B., Siciliano, P., Marletta, V., Monteriù, A. (2014). Ambient Assisted Living Italian Forum. Berlin: Springer.

Ally, M. (2004). Foundations of educational theory for online learning. In T. Anderson, \& F. Elloumi (Eds.), Theory and practice of online learning. Athabasca University.

Aune, B. (1996). Successful strategies for accommodating students with disabilities. Disability Compliance for Higher Education, 1(3).

Bates, A.W., Poole, G. (2003). Course development and maintenance. Effective teaching with technology in higher education. San Francisco: Jossey-Bass.

Berry, G., \& Mellard, D. (2002). Current status on accommodating students with disabilities in selected community and technical colleges: Fall 1999-Spring 2001. Lawrence, KS: University of Kansas.

Besio, S. (2006). Tecnologie assistive per la disabilità. Lecce: Pensa Multi Media.

Biggs, J. (2003). Teaching for quality learning at university: What the student does. Buckingham: SRHE and Open University Press.

Boud, D., Prosser, M. (2002). Appraising new technologies for learning: A framework for development. Educational Media International, 39(3), 237-245.

Buzza, D., Richards, L. (2005). LearningMapR: A prototype tool for creating IMS-LD compliant units of learning. Journal of Interactive Media in Education, 17, 1-14.

Cabral, L. (2013). L'orientamento accademico e professionale degli studenti universitari con disabilità. PhD thesis, Università degli Studi di Roma "Foro Italico", Rome, Italia.

Cafiero, J.M. (2009). Comunicazione aumentativa e alternativa. Trento: Erickson.

Cameron, L. (2010). Could pedagogical planners be a useful learning design tool for university lecturers? The University of the Fraser Valley Research Review, volume 3: issue 2 .

Cavallo, F., Marletta, V., Monteriù, A., Siciliano, P. (2017). Ambient Assisted Living Italian Forum 2016. Berlin: Springer.

CE, Comunità Europea - Helios II (1996). Enseignement Supérieur e t Etudiants Handicapés, Groupe Thématique 13 du Programme européen Helios II. Bruxelles: Commission Européenne.

Censis (giugno 2017). Accompagnare le Università verso una piu ampia integrazione degli studenti con disabilità e DSA". Survey presented at the Convention: "Presente 
e futuro dei servizi per l'inclusione: Atenei a confronto". Catania: Università degli Studi di Catania. CNUDD (2014), Linee Guida, Bergamo, www.cnudd.it (ultima consultazione 21 aprile 2018).

Compendium LD learning design software, http://compendiumld.open.ac.uk/, last access 2018 .

Conole, G., \& Weller, M. (2007). The Open University Learning Design Project. Proceedings of the European LAMS Conference 2007: Designing the Future of Learning. Greenwich, UK.

Cook, A.M., Hussey, S.M. (2002). Assistive Technologies Principles and Practice. Mosby St. Luois.

Cook, J. (2006). Symposium - Design in the disciplines. JISC Innovating e-Learning 2006: Transforming Learning Experiences Online Conference.

Cottini, L. (2007). Didattica speciale e integrazione scolastica. Roma: Carocci.

Ciaschini, M., De Angelis, M., Monteriù, A., Pretaroli, R., Severini, F., Socci, C. (2015). Investments and Sustainability of Public Expenditure in the Health Sector. In Andò B., Siciliano P., Marletta V., Monteriù A. (eds.). Ambient Assisted Living. Biosystems \& Biorobotics, vol. 11. Springer, Cham.

Ciaschini, M., De Angelis, M., Monteriù, A., Pretaroli, R., Severini, F., Socci, C. (2016). The Role of ICT in the Italian Health Care System. In Conti M., Martínez Madrid N., Seepold R., Orcioni S. (eds.). Mobile Networks for Biometric Data Analysis. Lecture Notes in Electrical Engineering, vol. 392. Springer, Cham.

de Anna, L. (2016). Le esperienze di integrazione e inclusionnelle università tra passato e presente. Milano: FrancoAngeli.

de Anna, L., Covelli A. (2018). La Didattica inclusiva nell’Università: innovazione e successo formativo degli studenti con Special Educational Needs. In Form@ re - Open Journal per la formazione in rete, 18(1): 333-345. DOI: http://dx.doi. org/10.13128/formare-22505.

DialogPlus Toolkit. http://edutechwiki.unige.ch/en/DialogPlus_Toolkit, last update 2014.

Dongming, Xu, Wayne, W. Huang, Huaiqing Wang, Jon Heales, Enhancing e-learning effectiveness using an intelligent agent-supported personalized virtual learning environment: An empirical investigation. Information \& Management, 51(4), 2014: 430-440, ISSN 0378-7206, https://doi.org/10.1016/j.im.2014.02.009.

Eradze, M., Laanpere, M. (2014). Interrelation between Pedagogical Design and Learning Interaction Patterns in different Virtual Learning Environments. In Zaphiris P., Ioannou A. (eds.). Learning and Collaboration Technologies. Technology-Rich Environments for Learning and Collaboration. LCT 2014. Lecture Notes in Computer Science, vol. 8524, Springer, Cham.

Faggioli, M. Tecnologie per la didattic. Milano: Apogeo.

Falconer, I. et al. (2007). Mod4L final report: Representing learning designs. London.

Fogarolo, F. (2007). Il computer di sostegno. Ausili Informatici a scuola. Trento: Erickson.

Fouzia, K.A. (2015). Use of Assistive Technologies in inclusive Education making room for diverse learning needs. Transcience, 6(2).

Giaconi, C. (2013). Elementos de didática inclusiva em classes com alunos com Dislexia. In Aparecida S., Dislexia, Brazil: WAK EDITORA. 
Giaconi, C. (2015). Qualità della vita e adulti con disabilità. Milano: FrancoAngeli. Goodyear, P. (2005). Educational design and networked learning: Patterns, pattern languages and design practice. Australasian Journal of Educational Technology, 21(1): 82-101.

Grainne, C. (2012). Designing for learning in an open world. Springer Science \& Business Media.

Hannafin, M., \& Land, S. (1997), The foundations and assumption of technologyenhanced student-centered learning environments. Instructional Science, 25: 167-202.

Heathcote, E. (2006), Learning design templates - A pedagogical just-in time support tool, JISC Innovating e-Learning 2006: Transforming Learning Experiences Online Conference.

Hurst, A. (1993). Steps towards graduation: access to higher education for people with disabilities. Aldershot: Ashgate Publishing Group.

JISC (2007). "Briefing Paper 1: MLEs and VLEs Explained", JISC.

Knight, S. (2004). Effective practice with e-learning: A good practice guide in designing for learning. www.jisc.ac.uk/media/documents/publications/effective practiceelearning. pdf Retrieved June 6, 2008.

Kurilovas, E., Kubilinskiene, S., Dagiene, V. (2014). Web 3.0 - Based personalisation of learning objects in virtual learning environments. Computers in Human Behavior, 30: 654-662, ISSN 0747-5632, https://doi.org/10.1016/j.chb.2013.07.039.

Laurillard, D. (2008). London Pedagogy Planner website. Retrieved February 10, 2008, from www.wle.org.uk/d41/.

Laurillard, D. (2002). Rethinking university teaching: A conversational framework for the effective use of learning technologies. London: Routledge Falmer.

Longhi, S., Siciliano, P., Germani, M., Monteriù, A. (2014). Ambient Assisted Living Italian Forum 2013. Berlin: Springer.

Longhi, S., Monteriù, A. (2015), Riflessi etici della formazione tecnico-scientifica. In Etica e senso di responsabilità nella professione. Istituto Grafologico Internazionale Girolamo Moretti a cura di Olivia Fagnani, vol. 169: 127-131.

Longhi, S., Ciabattoni, L., Ferracuti, F., Freddi, A., Monteriù, A., Ortenzi, D., Romeo, L. (2016). Tecnologie assistive per la vita indipendente. In La bioingegneria per il benessere e l'invecchiamento attivo. Patron Editore (Italy), Sep. 2016, pp. 415-428.

Longhi, S., Monteriù, A., Freddi, A. (2017). Human Monitoring, Smart Health and Assisted Living: Techniques and Technologies. The Institution of Engineering and Technology, IET.

Longhi S., Monteriù A. (2018), Quegli artisti che chiamiamo insegnanti. Innovatio Educativa, Vol. 1, pp. 30-3.

Mayes, T., de Freitas, S. (2001), Stage 2: Review of e-learning theories, frameworks and models, www.jisc.ac.uk/uploaded_documents/Stage_Learning_Models_ Version\%201).pdf.

Manton, M., Masterman, L. (2007), Getting started with Phoebe. Retrieved April 23, 2007, from http://phoebe-app.conted.ox.ac.uk/cgi-bin/trac.cgi/wiki/ PhoebeGettingStarted.

Marcellini, F., Giuli, C., Gagliardi, C., Papa, R. (2007). Ageing in Italy: urban-rural differences. In Archives of Gerontology and Geriatrics, 44: 243-260. 
McCreadie, C., Tinker, A. (2005). The acceptability of assistive technology to older people. Ageing \& Society, 25: 91-110.

McAlpine, I., Allen, B. (2007). Designing for active learning online with learning design templates. In ASCILITE Singapore 2007: Providing choices for learners and learning. Singapore. www.ascilite.org.au/conferences/singapore07/ procs/ mcalpine.pdf.

NAACE (2004), Leadership and coordination. Implementing ICT: A guide to implementing ICT in schools of the UK. www.naace.org/impict/leadership.html.

Oliver, R., Harper, B. et al. (2002). Formalising the description of learning designs. 2002 Annual International Conference of the Higher Education Research and Development Society of Australasia (HERDSA): Quality Conversations. Perth, Australia.

Phoebe Pedagogic Planner, www.phoebe.ox.ac.uk/, last update 2009.

Pinnelli, S. (2011). I servizi socio-educativi per fare integrazione. Lecce: Pensamultimedia.

Pinnelli, S. (2010). I ferri del mestiere. Le Tic nella riduzione del deficit visivo. In L. Piccolo (a cura di). La complessità dell'invisibile. Milano: FrancoAngeli: 124-137.

Quesenbery, W., Theofanos, M. (2005), Towards the Design of Effective Formative Test Reports, Journal of Usability Studies, 1(1), November: 28-46. www.upassoc. org/upa_publications/jus/2005_november/formative.html.

Ridolfi, P. (2001). Normative italiane sull'accessibilità al web (Presidenza del Consiglio dei ministri. Dipartimento della funzione pubblica: Circolare 13 marzo 2001, n. 3/2001 (G.U. Serie generale n. 065 del 19 marzo 2001).

Ramsden, P. (2003). Learning to teach in higher education. New York: Routledge Falmer.

Stark, J.S. (2000). Planning introductory college courses: Content, context and form. Instructional Science, 28: 413-438.

Sanchez Utgé, M., Mazzer, M., Pagliara, S., \& de Anna, L. (2017). La formazione degli insegnanti di sostegno sulle TIC. Analisi dei prodotti multimediali del corso di specializzazione per le attività di sostegno. Italian Journal of Special Education for Inclusion, 5(1): 133-146. 